\title{
The Role of Compatibilizers on the Properties of PC/ABS Alloy
}

\author{
Hao Duan1 ${ }^{*}$, Min-Qi Xin², Kwang-Yoon Kim1', Jun-Jie Tang1 \\ ${ }^{1}$ Fine-Blend Compatilizer Jiangsu Co. Ltd., Shanghai, China \\ ${ }^{2}$ Shanghai Kumhosunny Plastics Co. Ltd., Shanghai, China \\ Email: duanhao06@hotmail.com
}

How to cite this paper: Duan, H., Xin, M.-Q., Kim, K.-Y. and Tang, J.-J. (2017) The Role of Compatibilizers on the Properties of PC/ABS Alloy. Journal of Materials Science and Chemical Engineering, 5, 2130.

https://doi.org/10.4236/msce.2017.56003

Received: April 26, 2017

Accepted: June 16, 2017

Published: June 19, 2017

Copyright () 2017 by authors and Scientific Research Publishing Inc. This work is licensed under the Creative Commons Attribution International License (CC BY 4.0).

http://creativecommons.org/licenses/by/4.0/

\section{Open Access}

\begin{abstract}
Two compatibilizers consisting of styrene-acrylonitrile-glycidyl methacrylate (SAG) terpolymer with different contents of glycidyl methacrylate (GMA), SAG-001 (1 wt $\%$ of GMA) and SAG-005 (5 wt\% of GMA), and styrene-acrylonitrile-maleic anhydride terpolymer (SAM), SAM-002 (2 wt\% of maleic anhydride ), were used to evaluate the role of compatibilizers in the PC/ABS alloy in terms of the mechanical properties, thermal stability and phase morphology. The tensile strength of SAG modified PC/ABS alloy slightly increased than that of SAM modified system, but the two compatibilizers barely affected the flexural strength of the system. On the other hand, the impact strength of SAG modified PC/ABS was improved. In addition, the MFR (melt flow index) of the SAG modified PC/ABS alloy reduced, implying that the viscosity or molecular weight of the system increased. The HDT (heat distortion temperature) also improved with SAG modified system. Moreover, the phase morphology of the SAG modified PC/ABS alloys much enhanced than that of SAM modified system. As a consequence, SAG compatibilized PC/ABS alloy showed better properties than those of SAM modified system, suggesting that the reaction between carboxylic or epoxy groups in SAG and terminal carboxyl group in PC would be the main factor to bring the enhancement in the mechanical, thermal and morphological properties of the PC/ABS alloy.
\end{abstract}

\section{Keywords}

Compatibilizer, PC/ABS, SAG, SAM, Thermostability, Mechanical Property, Phase Morphology

\section{Introduction}

The enhanced properties of PC/ABS alloy were resulted from the combined characteristics of both PC and ABS. Compared to PC itself, the mobility and 
processability of PC/ABS alloy improved and the sensitivity to stress reduced. On the other hand, PC/ABS alloy possess excellent thermal stability compared to that of ABS. Thus, it can be widely applied to the various fields of household appliances, office equipments, communication equipments, camera and medical equipments, building and lightening appliances, aerospace, computers and optical fibers, etc. In particular, the property of high strength and heat resistance of $\mathrm{PC} / \mathrm{ABS}$ alloy is applicable to the automobile interiors, exteriors and light systems [1].

In recent years, the market of PC/ABS alloy has continuously grown $10 \%$ per year. In the mean time, more attractive appearance and higher performance of PC/ABS alloy were demanded in the automobile industry and household appliances. As a result, the new class of PC/ABS alloys was appeared [2] with excellent mechanical properties and enhancement in the stability of resistance to hydrolysis, free-spraying, ultra-low gloss, and resistance to chemicals and environmentally friendly property. Jae-Won Park [3] and Qian Ma [4] studied some new process of PC/ABS with glossy and metallic colored optical property, and their works substitute the conventional process in the automobile industry. Jia Wang [5] et al. studied the properties of recycled PC/ABS and obtained a branching structure using epoxy-based chain extender, which furnished a better utilization and processing properties for recycling. Y. T. Sung [6] et al. studied the stability of PC in PC/ABS and obtained that the molecular weight of PC significantly decreased due to talc. On the other hand, the shortfall was the technique of improving compatibility for the high performance of PC/ABS. Hyuk Jin Jung [7] et al. studied the phase morphology and interfacial tension of PC/ABS by investigating the content of acrylonitrile (AN) in SAN copolymer affecting the phase morphology and rheology. Other studies have shown that the mechanical properties and phase morphology of $\mathrm{PC} / \mathrm{ABS}$ were more or less improved, but enhanced with compatibilizer, SMA [8] [9] [10]. In addition, the reactivity between $\mathrm{MAH}$ groups and carboxyl end groups of polyester was somewhat limited [11] [12] [13] [14].

In this paper, two different compatibilizers with various contents were used in the PC/ABS (70/30) alloy and the role of compatibilizers on the properties of the $\mathrm{PC} / \mathrm{ABS}$ system was evaluated. One is SAG (styrene-acrylonitrile-glycidyl methacrylate) terpolymer consisting of 1 and $5 \mathrm{wt} \%$ of glycidyl methacrylate (GMA) and other is SAM (styrene-acrylonitrile-maleic anhydride) terpolymer containing of $2 \mathrm{wt} \%$ of maleic anhydride (MAH). Thus, the effect of SAG and SAM on the mechanical properties, thermal stability and phase morphology of PC/ABS alloy was compared and the main cause of compatibilization between the compatibilizer and alloy matrix was suggested.

\section{Experiment}

Materials. Polycarbonate (PC), as a lot number of 1100, was purchased from Honam Petrochemical Company, Korea and ABS, as a lot number of 8391, was purchased from Sinopec Shanghai Gaoqiao Company, China. Two styrene- 
acrylonitrile-glycidyl methacrylate (SAG) terpolymers, which are SAG-001 (1\% of GMA content, $\mathrm{M}_{\mathrm{w}} \approx 80,000-100,000 \mathrm{~g} / \mathrm{mol}$ ) and SAG-005 (5\% of GMA content, $\mathrm{M}_{\mathrm{w}} \approx 80,000-100,000 \mathrm{~g} / \mathrm{mol}$ ), are products of Fine-Blend Compatilizer Jiangsu Co., Ltd., China. Styrene-acrylonitrile-maleic anhydride (SAM) terpolymer, as a lot number of SAM-002 ( $2 \%$ of MAH content, $\mathrm{M}_{\mathrm{w}} \approx 100,000$ ) is also a product of Fine-Blend Compatilizer Jiangsu Co., Ltd., China. Antioxidant, as a lot number of 168,245 , is a product from the Ciba Specialty Chemicals, Swiss. All these ingredients are used as received.

Sample preparation. Both of $\mathrm{PC}$ and $\mathrm{ABS}$ resins were dried at $90^{\circ} \mathrm{C}$ for $8 \mathrm{~h}$ using an oven. $\mathrm{PC}$ and $\mathrm{ABS}$ were first mechanically mixed in the ratio of 70:30, respectively, with antioxidant, $168(0.2 \mathrm{wt} \%), 245(0.2 \mathrm{wt} \%)$, before the extrusion process. Then, this mixture was again mixed with different ratios of SAG and SAM using a high speed mixer. They were put into twin-screw extruder for melt mixing. The temperature for each stage was $180^{\circ} \mathrm{C}, 200^{\circ} \mathrm{C}, 220^{\circ} \mathrm{C}, 235^{\circ} \mathrm{C}, 240^{\circ} \mathrm{C}$, $245^{\circ} \mathrm{C}, 250^{\circ} \mathrm{C}$ from the head to the end of the extruder. Then, the extrusion, cooling and pelletizing processes were followed by. The pelletized granules were dried at $90^{\circ} \mathrm{C}$ for $8 \mathrm{~h}$ in an oven and injection molded to prepare the standard sample specimens. The sample size was the following; for tensile strength $165 \times$ $13 \times 3.2 \mathrm{~mm}$ according to the ASTM D638-2010, for bending $127 \times 12.7 \times 3.2$ $\mathrm{mm}$ according to the ASTM D 790-2010, for Izod impact strength $63.5 \times 12.7 \times$ $3.2 \mathrm{~mm}$ according to the ASTM D256-2010.

All ingredients for PC/ABS alloy upon sample numbers are listed in Table 1. For example, 1\# consists only of PC/ABS (70/30) with $3 \mathrm{phr}$ of antioxidant, 168,245. 4\# consists of PC/ABS (70/30), $3 \mathrm{phr}$ of antioxidant, 168,245 and $5 \mathrm{phr}$ of SAG-005. The pelletized particles were dried at $100^{\circ} \mathrm{C}$ for $3 \mathrm{~h}$, then various testing specimens and templates were prepared at $25^{\circ} \mathrm{C}$.

Equipments \& experiments. High speed mixer, SH140Ф85 of Zhanghiagang Baixiongkemei Machinery Co. Ltd, China, twin-screw extruder (CTE50-TY3515, diameter $36 \mathrm{~cm}$, length/diameter ratio 40/1, respectively) of Nanjing Corporation Machinery Co. Ltd., China, electronic universal testing machine, CMT6104, of Shenzhen Xingsansi Measurement Technique Co. Ltd, China, Izod impact testing machine, XJU-22, of Chengde Testing Machine Co. Ltd, China, melt flow indexer, RL-11B, of Shanghai Sierda Scientific Instrument Co. Ltd., China, injection molding machine, JN88-E, of Zhenxiong Machinery Co. Ltd., China and

Table 1. The chemical compositions of PC/ABS alloy upon sample numbers.

\begin{tabular}{cccccc}
\hline Sample Number & $1 \#$ & $2 \#$ & $3 \#$ & $4 \#$ & $5 \#$ \\
\hline PC & 70 & 70 & 70 & 70 & 70 \\
ABS & 30 & 30 & 30 & 30 & 30 \\
SAG-001 (phr) & & 0.3 & 0.5 & & \\
SAG-005 (phr) & & & & 0.5 & \\
SAM-002 (phr) & & & & & 0.5 \\
$168,245(\mathrm{phr})$ & 0.3 & 0.3 & 0.3 & 0.3 & 0.3 \\
\hline
\end{tabular}


scanning electron microscope, JSM-6360LV, of Japan Electronic Company were used.

Tensile strength was evaluated based on the standard ASTM D638-2010 at tensile speed of $5 \mathrm{~mm} / \mathrm{min}$. Flexural strength was tested according to ASTM D790-2010 using the flexural speed of $2 \mathrm{~mm} / \mathrm{min}$. The Izod impact strength was performed according to ASTM D256-2010 (1/4 inch specimen's size: $63.5 \mathrm{~mm}^{*}$ $12.7 \mathrm{~mm}^{\star} 6.4 \mathrm{~mm}, 1 / 8$ inch specimen's size: $63.5 \mathrm{~mm}^{\star} 12.7 \mathrm{~mm} * 3.2 \mathrm{~mm}$,). MFR was evaluated based on ASTM D1238-2010 at $260^{\circ} \mathrm{C}$ and $5 \mathrm{~kg}$ of load. The standard ASTM D648-2007 was used to test the heat distortion temperature (HDT) at the load of 1.82MPa. Scanning electron microscopy (SEM) was used to study the morphological characteristics. Fractured surface was obtained after dealing with liquid nitrogen. The cross section was etched by $\mathrm{K}_{2} \mathrm{Cr}_{2} \mathrm{O}_{7}-\mathrm{H}_{2} \mathrm{SO}_{4}$ solvent and treated with spray-gold. The acceleration voltage was $60 \mathrm{kV}$ when the surface morphology of fault was observed by SEM.

The experimental values are the average of at least five measurements.

\section{Results and Discussion}

The effect of compatibilizers on PC/ABS alloy. As shown in Figure 1, the effects of compatibilizers on the tensile and flexural strength were studied.

The compatibilizers, SAG-001, SAG-005 and SAM-002 were added in samples 2\#-5\#. As seen in Figure 1(a), the tensile strength of 1\#, which contains no compatibilizer, was $55.5 \mathrm{MPa}$, while that of $2 \#-5 \#$ varied from 57 to $58 \mathrm{MPa}$, implying that no big difference in the tensile strength of the specimens with different compatibilizers and contents was observed. Since the solubility parameters of PC and ABS are similar (that of ABS is $19.6-20.8$ and that of PC is 19.4 $\mathrm{cal} / \mathrm{cm}^{3}$ ) [10], it was suggested that they would be partially miscible. In addition, in Figure 1(b), the flexural strength of PC/ABS alloy also showed no difference upon different compatibilizers and contents.

Figure 2 shows the Izod impact strength of PC/ABS with $1 / 8$ and $1 / 4$ inch thickness. As seen in Figure 2(a), the impact strength of 1/8 inch of PC/ABS without compatibilizer (specimen $1 \#$ ) was $514 \mathrm{~J} / \mathrm{m}$, but this value increased to $584,602,628$ and $594 \mathrm{~J} / \mathrm{m}$ for specimens from $2 \#$ to $5 \#$, respectively. Thus, the Izod impact strength of thin PC/ABS alloy was directly influenced by sorts and contents of compatibilizers. Here, 5 phr of SAG-005 modified PC/ABS showed the highest impact strength. On the other hand, for $1 / 4$ inch of PC/ABS alloy, the impact strength of $1 \#$ was $180 \mathrm{~J} / \mathrm{m}$, and that of specimen $2 \#, 3 \#, 4 \#$ and $5 \#$ varied to 286, 301, 309 and $227 \mathrm{~J} / \mathrm{m}$, respectively. Again, $5 \mathrm{phr}$ of SAG-005 modified PC/ABS alloy showed the highest impact strength. From these results, it was concluded that the specimen $4 \#$ with $1 / 8$ and $1 / 4$ inch of thickness showed the highest impact strength and specimen 5\# showed the poorest impact strength. This result indicates that the impact strength of SAG modified PC/ABS alloy was much more enhanced than that of SAM modified system.

Since SAG contains of glycidyl methacrylate (GMA) group, GMA can react with the terminal hydroxyl group in PC as described in Scheme 1. On the other 


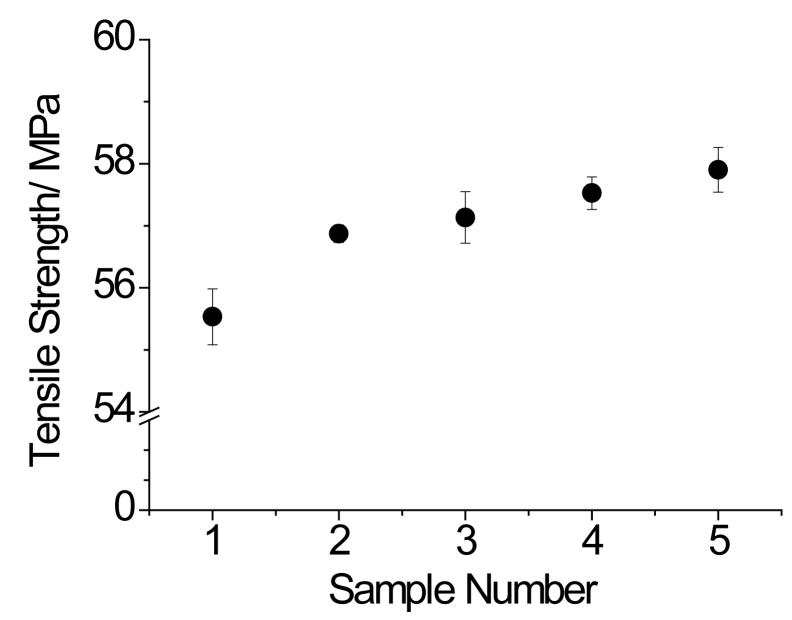

(a)

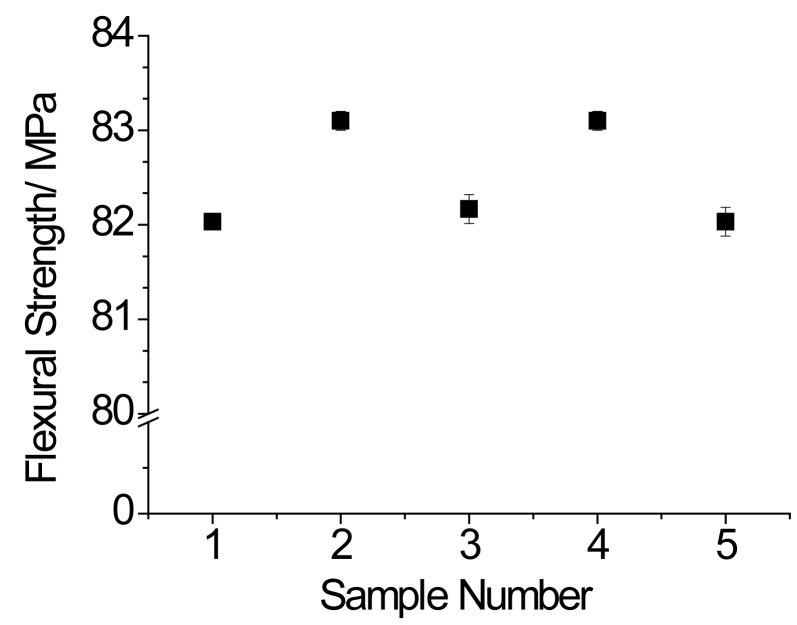

(b)

Figure 1. The tensile strength (a) and flexural strength (b) of PC/ABS alloy with different contents of compatibilizers ( $\bullet$ : tensile strength, $\bullet$ : flexural strength).

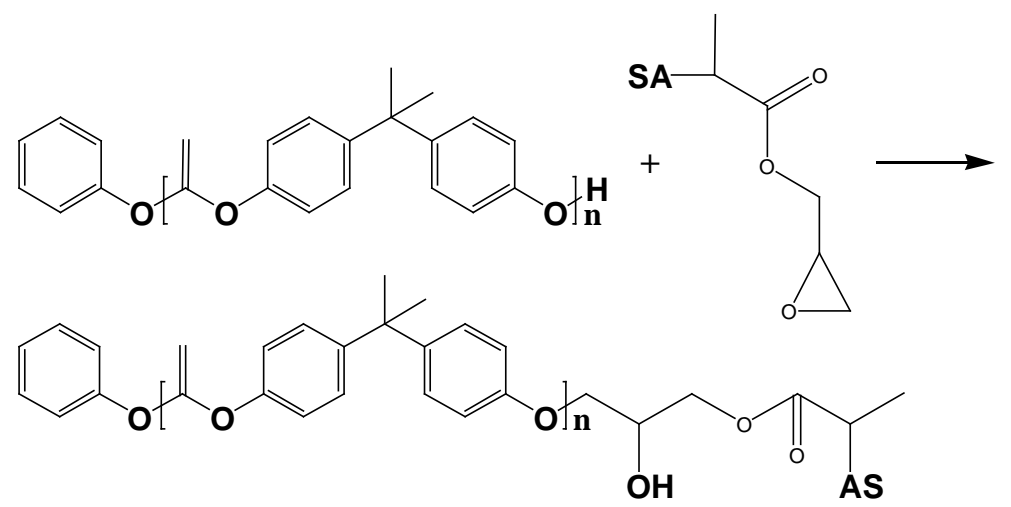

Scheme 1. Schematic diagram of the reaction between PC terminal groups and GMA in SAG.

hand, MAH in SAM reacts with hydroxyl-terminated group in PC described in Scheme 2. Since five-member MAH group in SAM is more rigid than threemember epoxy group GMA in SAG, it was suggested that the reactivity of SAG 


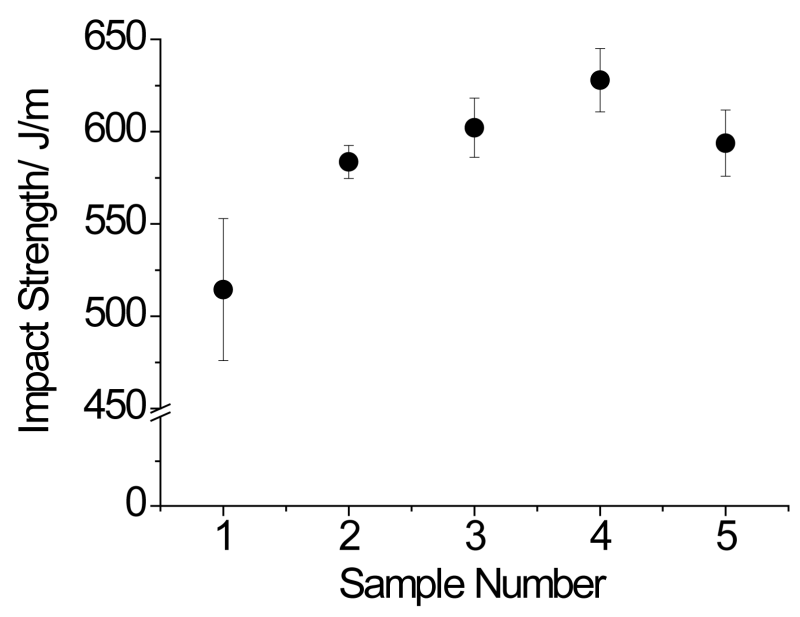

(a)

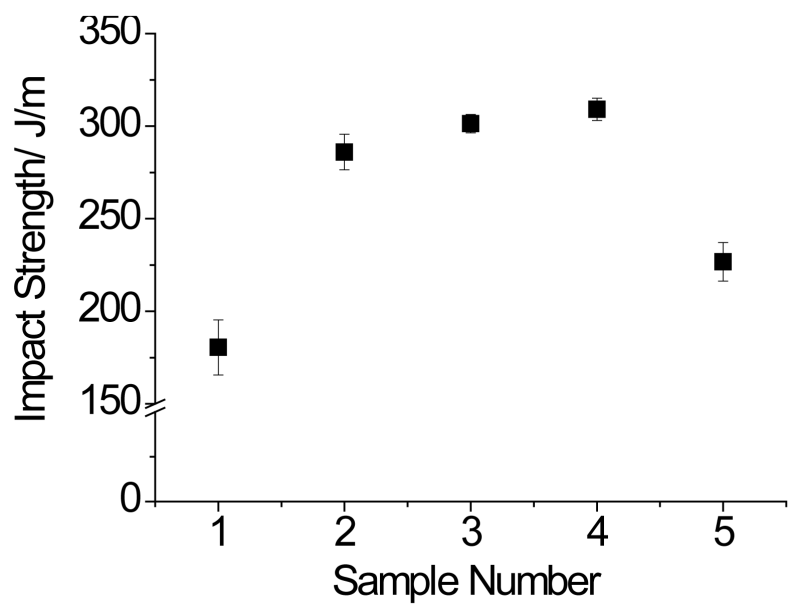

(b)

Figure 2. The impact strength of PC/ABS with different compatibilizer. (a) •: impact strength with $1 / 8$ inch thickness; (b) - impact strength with $1 / 4$ inch thickness.
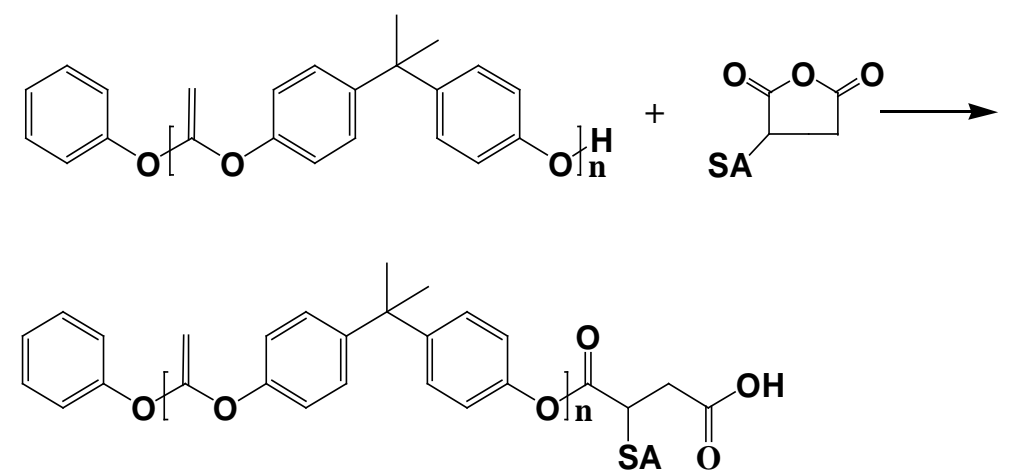

Scheme 2. Schematic diagram of the reaction between hydroxyl-terminated of PC and $\mathrm{MAH}$ in SAM.

would be higher than that of SAM, resulting in higher impact strength.

From the discussion of Figure 2 and Scheme 1 and Scheme 2, the impact strength increased with the increasing contents of SAG. In addition, the common features are the following. First, the larger the compatibilizer content, the 
higher the impact strength was observed as seen in 2\# and 3\#, and 4\#. Second, using the same content of compatibilizer, the impact strength of SAG-005 was higher than that of SAG-001 or SAM-002, meaning that the larger the GMA content which is $5 \mathrm{wt} \%$, the higher the impact strength was obtained as seen in 4\#. Third, the impact strength of SAG modified PC/ABS alloy was higher than SAM modified system due to the higher reactivity between GMA in SAG and carboxylic group in PC than that between MAH in SAM and carboxylic acid in PC. This relationship is well described in Scheme 1 and Scheme 2.

The MFR (melt flow index) and HDT were measured for each specimen and the results are drawn in Figure 3. As seen in Figure 3(a), the MFR of the specimen 1\#, 2\#, 3\#, 4\# and 5\# was 29, 24, 24, 23 and $25 \mathrm{~g} / 10 \mathrm{~min}$, respectively. Thus, the MFR of the compatibilizer modified PC/ABS system slightly decreased, meaning that the molecular weight or the melt viscosity of PC/ABS alloy increased with the addition of compatibilizers. Thus, it was suggested that the reaction between the epoxy groups of SAG and the carboxylic terminal group of PC, as shown in Scheme 1 and Scheme 2, respectively, would cause the increased molecular weight or melt viscosity of PC/ABS, resulting in lowering MFR value.

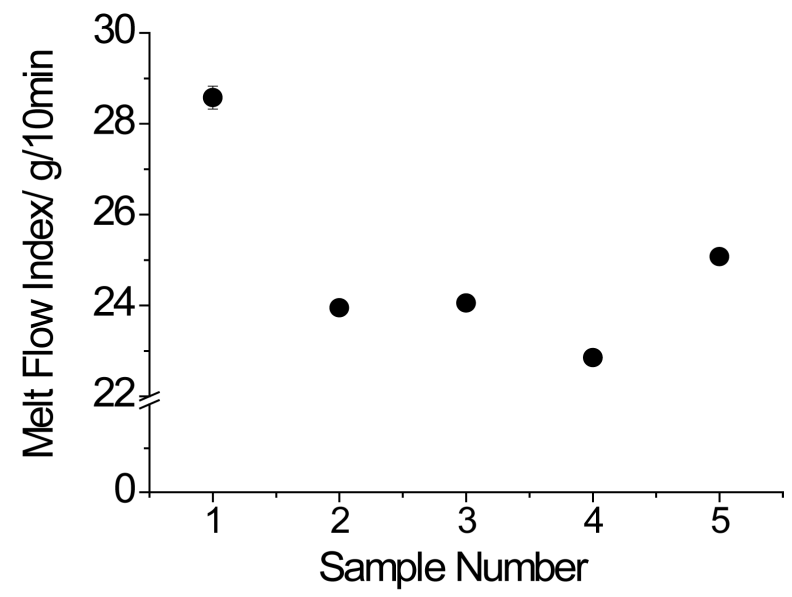

(a)

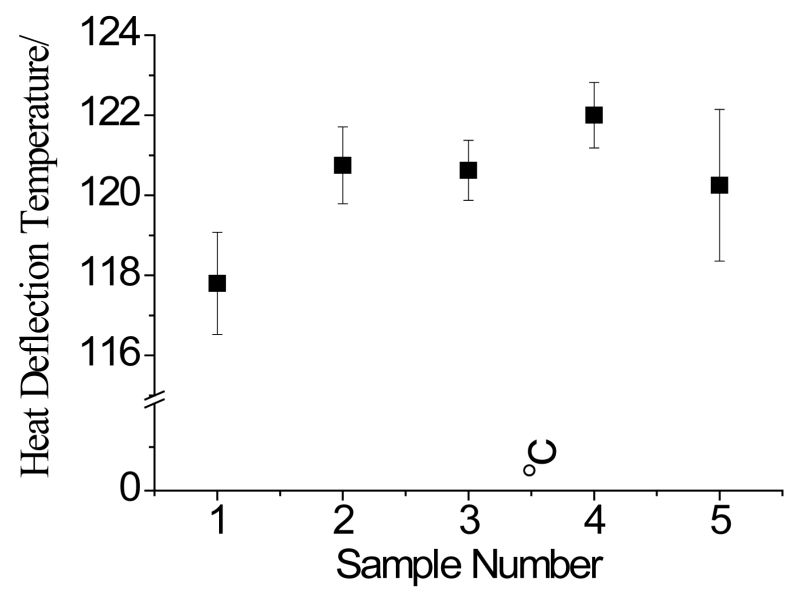

(b)

Figure 3. The MFR (a) and HDT (b) of PC/ABS with different compatibilizers. 
As seen in Figure 3(b), the HDT slightly increased; those values of 1\#, 2\#, 3\#, 4\# and 5\# was $118^{\circ} \mathrm{C}, 121^{\circ} \mathrm{C}, 121^{\circ} \mathrm{C}, 122^{\circ} \mathrm{C}$ and $120^{\circ} \mathrm{C}$, respectively. Thus, the enhancement of HDT would be caused from the thermotolerance of PC/ABS alloy due to the reaction between GMA or MAH and carboxylic group.

The phase morphology of PC/ABS alloy. The phase morphology of PC/ABS alloy with different compatibilizers was shown from Figure 4(a) to Figure 4(e) for specimens from $1 \#$ to $5 \#$, respectively. Compared to the ABS domain in the PC/ABS alloy without any compatibilizer [Figure 4(a)], the phase morphology of ABS in PC matrix showed much enhancement in regularity and homogeneity. A new structure like bicontinuous phase was formed in Figure 4(d) and this is also rationalized as the higher reactivity between GMA groups in SAG and carboxylic group in PC.

The data representing the effect of compatibilizers on the mechanical property of PC/ABS is listed in Table 2. The observed property of the specimen $4 \#$ was

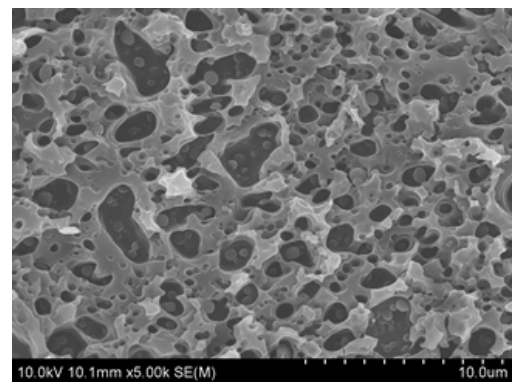

(a)

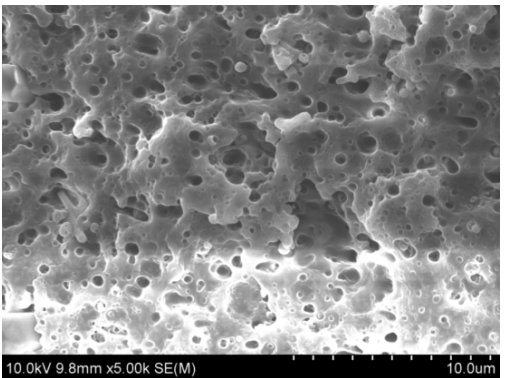

(c)

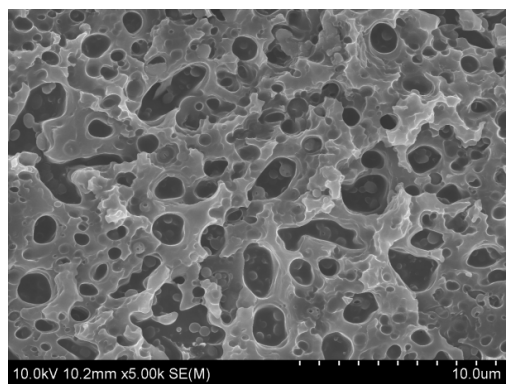

(b)

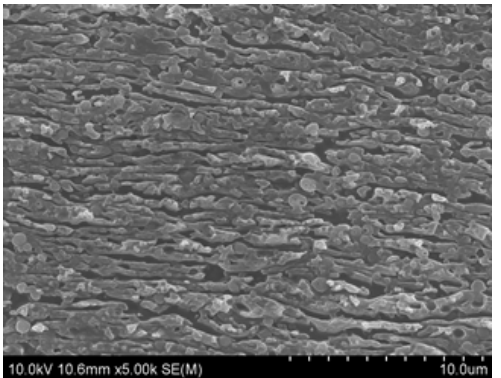

(d)

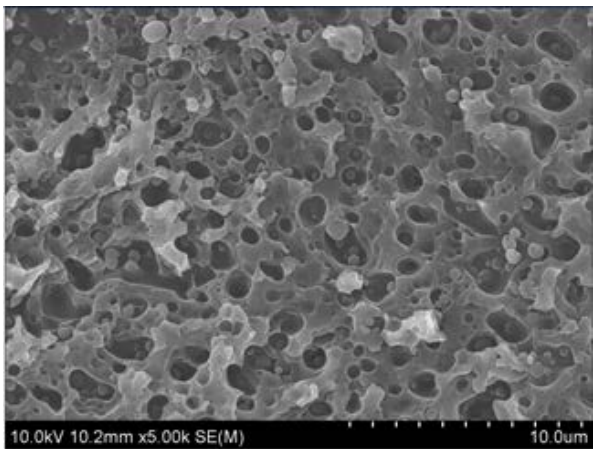

(e)

Figure 4. The SEM morphology showing the influence of different compatibilizers and contents of them in PC/ABS (70/30) alloy. Samples for (a) 1\#; (b) 2\#; (c) 3\#; (d) 4\#; and (e) $5 \#$. 
Table 2. Mechanical and thermal properties of the specimens.

\begin{tabular}{cccccc}
\hline Specimen No. & $1 \#$ & 2\# & $3 \#$ & $4 \#$ & $5 \#$ \\
\hline Property & 56 & 57 & 57 & 58 & 58 \\
Tensile strength & 82 & 83 & 82 & 83 & 82 \\
Flexural strength & 514 & 584 & 602 & 628 & 594 \\
Impact strength (1/8”) & 180 & 286 & 301 & 309 & 227 \\
Impact strength (1/4") & 29 & 24 & 24 & 23 & 25 \\
Melt index & 118 & 121 & 121 & 122 & 120 \\
HDT & & & & &
\end{tabular}

the best among 5 samples, implying that GMA-contained SAG terpolymer is an excellent compatibilizer in PC/ABS (70/30) system. It can be explained that the micro morphology phase was optimized due to the introduction of SAG inducing the dispersed particle smaller and the distribution more homogeneous than with SAM. As a consequence, more energy can be absorbed and stored when the alloy was affected by external forces, which resulted in the increased impact strength and less sensibility to gaps [1] [15].

\section{Conclusion}

The two compatibilizers consisting of styrene-acrylonitrile-glycidyl methacrylate terpolymer (SAG) with 1 and $5 \mathrm{wt} \%$ of glycidyl methacrylate (GMA) and one SAM (styrene-acrylonitrile-maleic anhydride terpolymer) with 2 wt $\%$ maleic anhydride (MAH) were used to evaluate the role as a compatibiulizer in PC/ABS (70/30) alloy based on the mechanical properties, thermal stability and phase morphology. The tensile strength of compatibilized PC/ABS alloy slightly increased, but the two compatibilizers barely affected the flexural strength of the system. On the other hand, the impact strength of SAG modified PC/ABS was improved, in particular, the specimen $4 \#$ with $0.5 \mathrm{phr}$ of SAG-005 showed much enhancement. In addition, the HDT of the specimen $4 \#$ showed $3^{\circ} \mathrm{C}$ increment. Moreover, the MFR of 4\# alloy reduced, implying that the viscosity or molecular weight of the system increased due to the interaction between compatibilizer and PC/ABS alloy. Moreover, the phase morphology of the specimen 4\# also showed the best indicating the small domain size and homogeneous dispersion of ABS in PC matrix, resulting in better compatibility. As a conclusion, the reactivity between GMA in SAG and terminal carboxyl group of PC would be the main factor for not only improving the mechanical and thermal property, but also enhancing the phase morphology of PC/ABS alloy.

\section{References}

[1] Yu, J., Ma, Z.R., Ling, X.L. and Guo, Z.X. (2007) Phase Morphology Evolvement and Properties of High Flow ability PC/ABS Alloy. Plastics, 36, 1.

[2] Zhou, K.S. and Lan, H. (2004) Research Development and Application of PC/ABS in Automobile. Automobile Technology \& Material, 12, 21.

[3] Park, J.W., Lee, J.S., Lee, B.H., Kim, M.K., Moon, B.S., Lee, C.Y. and Choi, B.H. 
(2013) Modifications of Optical Properties of PC/ABS by Dual Ions Beam Irradiation. Radiation Physics and Chemistry, 84, 126-128.

https://doi.org/10.1016/j.radphyschem.2012.06.032

[4] Ma, Q., Zhao, W.X., Li, X.R., Li, L.S. and Wang, Z.L. (2013) Study of an Environment-Friendly Surface Pretreatment of ABS-Polycarbonate Surface for Adhesion Improvement. International Journal of Adhesion and Adhesives, 44, 243-249. https://doi.org/10.1016/j.ijadhadh.2013.03.010

[5] Wang, J., Li, Y.C., Song, J.F., He, M.Y., Song, J.J. and Xia, K. (2015) Recycling of Acrylonitrile Butadiene Styrene (ABS) Copolymers from Waste Electrical and Electronic Equipment (WEEE), through Using an Epoxy-Based Chain Extender. Polymer Degradation and Stability, 112, 167.

https://doi.org/10.1016/j.polymdegradstab.2014.12.025

[6] Sung, Y.T., Fasulo, P.D., Rodgers, W.R., Yoo, Y.T., Yoo, Y. and Paul, D.R. (2012) Properties of Polycarbonate/Acrylonitrile-Butadiene-Styrene/Talc Composites. Journal of Applied Polymer Science, 124, 1020-1030. https://doi.org/10.1002/app.35147

[7] Jung, H.J., Son, Y. and Park, O.O. (2012) Influence of Acrylonitrile Content in Styrene-Acrylonitrile Copolymer on the Phase Morphology and Interfacial Tension in Blends of Polycarbonate/Styrene-Acrylonitrile Copolymer. Macromolecular Research, 22, 146. https://doi.org/10.1007/s13233-014-2026-9

[8] Fu, Z.R., Wang, F., Zhang, Y.H. and Yu, J.Y. (2000) Study on ABS/PC/SMAH Ternary Alloy. Engineering Plastics Application, No. 9, 7.

[9] Yin, N.W., Zhang, Y.X., Zhang, X.F. and Zhou, W. (2007) Preparation and Research of Property of PC/SAN/PB-g-SAN Alloy. China Plastics Industry, 35, 33.

[10] Wang, R.W., Yang, W.M. and Xin, M.Q. (2011) ABS Resin and Its Application. Chemical industry press, Beijing, 228-230.

[11] Cai, C.G., Chen, Y.K. and Jia, D.M. (2004) Study on Property of ABS/PC Polymer Blends. China Plastics Industry, 32, 24.

[12] He, N.N. and Liu, J.L. (2007) Application of Compatibilizers in PC/ABS Alloy. Plastic Science \& Technology, 35, 70 .

[13] Wang, J.F., Zhou, H.J. and Jiang, L.P. (2001) Influence of Compatibilizers on the Property of PC/ABS Alloys. Engineering Plastics Applications, No. 6, 1.

[14] Yang, Q., Zheng, Y.Q., Feng, Q. and Li, G.X. (2003) Study on PC/ABS Blends. Plastic Science \& Technology, 157, 58.

[15] Zhang, W. and Yu, Q. (2005) Study on Thermodynamic Miscibility of PC/ABS Alloys. Modern Plastics Processing and Applications, 17, 20. 
Submit or recommend next manuscript to SCIRP and we will provide best service for you:

Accepting pre-submission inquiries through Email, Facebook, LinkedIn, Twitter, etc. A wide selection of journals (inclusive of 9 subjects, more than 200 journals)

Providing 24-hour high-quality service

User-friendly online submission system

Fair and swift peer-review system

Efficient typesetting and proofreading procedure

Display of the result of downloads and visits, as well as the number of cited articles Maximum dissemination of your research work

Submit your manuscript at: http://papersubmission.scirp.org/

Or contact msce@scirp.org 